\title{
Development of the Perceived Stress Inventory: A New Questionnaire for Korean Population Surveys
}

\author{
Eon Sook Lee', Ho Cheol Shinn ${ }^{2 *}$, Jun Hyung Lee', Yun Jun Yang', Jung Jin Cho ${ }^{3}$, Gwiyeoroo Ahn', Yeong Sook Yoon', \\ Eunju Sung ${ }^{2}$ \\ 'Department of Family Medicine, Inje University Ilsan Paik Hospital, Inje University College of Medicine, Goyang, Korea \\ ${ }^{2}$ Department of the Family Medicine, Kangbuk Samsung Hospital, SungKyunKwan University School of Medicine, Seoul, Korea \\ ${ }^{3}$ Department of Family Medicine, Hallym University Dongtan Sacred Heart Hospital, Hallym University College of Medicine, Hwaseong, Korea \\ ${ }^{4}$ Kangnam University Graduate School of Education, Yongin, Korea
}

Background: Given emerging evidence of the association between stress and disease, practitioners need a tool for measuring stress. Several instruments exist to measure perceived stress; however, none of them are applicable for population surveys because stress conceptualization can differ by population. The aim of this study was to develop and validate the Perceived Stress Inventory (PSI) and its short version for use in population surveys and clinical practice in Korea.

Methods: From a pool of perceived stress items collected from three widely used instruments, 20 items were selected for the new measurement tool. Nine of these items were selected for the short version. We evaluated the validity of the items using exploratory factor analysis of the preliminary data. To evaluate the convergent validity of the PSI, 387 healthy people were recruited and stratified on the basis of age and sex. Confirmatory analyses and examination of structural stability were also carried out. To evaluate discriminatory validity, the PSI score of a group with depressive symptoms was compared with that of a healthy group. A similar comparison was also done for persons with anxious mood.

Results: Exploratory factor analysis supported a three-factor construct (tension, depression, and anger) for the PSI. Reliability values were satisfactory, ranging from 0.67 to 0.87 . Convergent validity was confirmed through correlation with the Perceived Stress Scale, Center for Epidemiologic Studies Depression Scale, and State-Trait Anxiety Inventory. People with depressive or anxious mood had higher scores than the healthy group on the total PSI, all three dimensions, and the short version.

Conclusion: The long and short versions of the PSI are valid and reliable tools for measuring perceived stress. These instruments offer benefits for stress research using population-based surveys.

Keywords: Stress; Measurement; Factor Analysis, Statistical; Validity; Reliability 


\section{INTRODUCTION}

There are emerging concerns about the associations between stress and related conditions, such as cardiovascular disease, depression, and cancer. ${ }^{1-4)}$ Early research has measured stress in different ways: external stressors, stress responses, and resilience. Contrary to the early focus on external stressors such as life events, current research commonly measures perceived stress, such as an individual's stress appraisal or emotional response. Many studies have shown an inconsistent picture of the effects of external stressors on health; therefore, recent studies have emphasized stress response, especially perceived stress. ${ }^{5)}$

Approaching this challenge, Levenstein et al. ${ }^{6}$ developed the Perceived Stress Questionnaire (PSQ) to assess perceived stress in terms of the cognitive, emotional, and symptomatic sequelae of a stress event. Factor analysis showed seven scales for the PSQ (harassment, overload, irritability, lack of joy, fatigue, worry, and tension). Follow-up studies of the PSQ revealed another psychometric construct in a large and diverse population. ${ }^{7)}$ The conceptualization of stress appears to vary according to the population.

Koh et al. ${ }^{8)}$ developed the Stress Response Inventory (SRI) and the Stress-induced Cognition Scale (SCS). ${ }^{9)}$ The SRI is a measurement tool that comprehensively focuses on four different types of stress responses, including cognitive reactions. Koh et al. ${ }^{8)}$ proposed this tool to measure individual response to a threat. The SCS, focusing on the cognitive dimension, has 21 items and three factors (extreme-negative thoughts, aggressivehostile thoughts, and self-depreciative thoughts). The SRI and SCS might be good instruments to measure stress reactions in the Korean population; however, they were developed using a small population recruited from one hospital. In addition, a subsequent psychometric study of the SRI showed a difference from the original structure using a large population of workers, but most of those subjects were young men. Therefore, further study using a general population is necessary to generalize the $\mathrm{SRI}^{10)}$ because the results of stress-measuring instruments might vary with sex and age. Validation studies of a new stress questionnaire developed using a healthy population similar in age and sex composition to census data could support a better instrument to evaluate stress in the general population.

Selecting a questionnaire for use in a large-scale survey or clinical practice study requires consideration of its length because a long questionnaire can place an unacceptable burden on survey participants or patients. ${ }^{11)}$ Therefore, it is of practical importance to identify whether short versions are appropriate for discriminating factors of clinical importance. The purpose of this study was to develop a new instrument with a short version in order to measure perceived stress in a large-scale population survey.

\section{METHODS}

\section{Development of a New Instrument of Perceived Stress}

First, a consensus survey using the Delphi method was used to determine the questions important in measuring stress. The responses to two rounds of surveys from 17 stress experts in Korea were collected. Those experts recommended measuring perceived stress with population-based surveys in stress research and suggested using the items of the PSQ, SCS, and SRI as the pool for a new instrument. A research team of 8 psychologists and stress research experts reviewed and agreed with the results of the consensus survey. All 81 items in the item pool were thus included for the new questionnaire development before excluding several overlapping items. Responses to these items were arranged into a Likert-type format: 'not at all (1 point), 'somewhat ( 2 points),' 'moderately (3 points),' 'very much (4 points),' and 'absolutely (5 points).'

Next, a preliminary study was conducted to create a questionnaire using 373 college students and healthy volunteers from several hospitals as subjects. The subjects had a mean age of $35.2 \pm 10.5$ years (range, 21 to 73 years); $48.7 \%$ of them were married; $46.9 \%$ were female; and $86.9 \%$ of them were college graduates. Exploratory factor analysis (EFA) was employed to select the most important items from the pool.

The EFA of the preliminary data yielded 12 subscales with eigenvalues greater than 1 . Among them, the 8 subscales of harassment, worry, tension, anger, aggression, depression, lack of joy, and loss of self-esteem were accepted as representing perceived stress by the research team. The excluded subscales were two types of somatization factors and external stressors. The items showing higher factor loading (>0.5) and higher item-total correlation were selected from the 8 subscales, with 1-4 items selected from each subscale. In total, 20 items were selected for the Perceived Stress Inventory (PSI) (Appendix 1).

\section{Validation Study of Perceived Stress Inventory}

Participants in the validation study were 387 individuals from several hospitals, recruited by advertisements. Most of them were patients or caregivers associated with the outpatient clinic or family members of hospital employees. We recruited as subjects only patients who were visiting the hospital for a regular health check-up or medical certificate and excluded volunteers with inappropriate conditions such as a severe disability or acute cardiac disease. The presence of many diseases that are influenced by stress reactions, such as infection, hyperthyroidism, irritable bowel syndrome, diabetes mellitus, and hypertension, along with psychiatric disease, such as depression or anxiety, and use of any medication affecting the stress response, such as nonsteroidal anti-inflammatory drugs, estrogen, steroids, or codeine, were also grounds for exclusion. We recruited to match the age and sex composition of the 2009 yearly population, in 
terms of expected change from the 2005 census data. ${ }^{12)}$ All subjects agreed to participate in the study by signing an informed consent form and answering the questionnaire; they also received a written explanation of the study. Of the total participants, 48 randomly selected subjects agreed to repeat the test 2 weeks later. The study protocol was approved by institutional review board of Inje University Hospital (approval no. IB-1008-037).

All enrolled participants were included in the analysis. Participants completed both the 20 -item and short 9 -item versions of the PSI. All subjects also completed the Korean version of the Perceived Stress Scale (PSS), ${ }^{13)}$ the Korean version of the Daily Stress Inventory (DSI), ${ }^{14,15)}$ the Korean version of the PSQ, ${ }^{16)}$ and the SRI. ${ }^{8)}$ Depressive mood or anxiety and quality of life (QoL) were also measured using the Center for Epidemiologic Studies Depression Scale (CES-D), ${ }^{17)}$ State-Trait Anxiety Inventory (STAI), ${ }^{18)}$ and Euro QoL (EQ5D) index and visual analog scale. ${ }^{19)}$ The test-retest reliability of the preliminary questionnaire was calculated using the results of the first and second tests over the 2 -week interval.

\section{Statistical Analysis}

Factor analysis was performed using varimax orthogonal rotation following a principal component analysis, and only the factors with an eigenvalue greater than 1 were retained in the final model. Depression, anxiety, and QoL were subjected to Pearson's correlation analysis in order to determine their relationships with the PSI scores. Pearson's correlation was also employed to assess the relationships between the PSI scores and the SRI, PSQ, and PSS scores. The comparison groups for the discriminant validity test were composed of subjects with depressive symptoms (CES-D score 21 or higher) ${ }^{17)}$ and a group of healthy adults, defined as subjects without depressive symptoms (CES-D score less than 21). We also compared the scores between an anxious group (STAI score 57 or higher) ${ }^{18)}$ and a healthy group. The comparison of PSI scores according to mood was performed using Student t-test. The test-retest reliability of the PSI was calculated using Pearson's correlation and Kappa statistics at the first and second testing sessions. Cronbach's $\alpha$ was calculated to measure the internal consistency of the dimensions and the total score. Confirmatory factor analysis determined the suitability of the 20 questions selected by the EFA. The IBM SPSS statistics program ver. 21.0 (IBM Co., Armonk, NY, USA) was used to analyze the data.

\section{RESULTS}

\section{Participants in the Validity Study of the Perceived Stress Inventory}

A total of 387 subjects aged 20 years or older were randomly selected from two hospitals, one in a metropolitan city and the other in a province. Of these subjects, $53.2 \%$ were female. The
Table 1. General characteristics of study population ( $\mathrm{N}=387$ )

\begin{tabular}{|c|c|c|c|}
\hline Characteristic & Male $(\mathrm{N}=181)$ & Female $(\mathrm{N}=206)$ & P-value \\
\hline Age (y) & $43.10 \pm 13.34$ & $44.64 \pm 14.42$ & 0.278 \\
\hline Body mass index $\left(\mathrm{kg} / \mathrm{m}^{2}\right)$ & $23.93 \pm 2.71$ & $22.15 \pm 3.20$ & $<0.001$ \\
\hline $\begin{array}{l}\text { Education state } \\
\leq \text { High school } \\
\geq \text { College }\end{array}$ & $\begin{array}{r}57(31.8) \\
122(68.2)\end{array}$ & $\begin{array}{r}113(57.1) \\
85(42.9)\end{array}$ & $<0.001$ \\
\hline $\begin{array}{l}\text { Family income (10 thousands) } \\
<300 \\
\geq 300\end{array}$ & $\begin{array}{l}55(38.5) \\
88(61.5)\end{array}$ & $\begin{array}{l}87(54.0) \\
74(46.0)\end{array}$ & 0.008 \\
\hline Marital status (married) & $132(74.2)$ & $132(67.7)$ & 0.174 \\
\hline $\begin{array}{l}\text { Occupation } \\
\text { Work } \\
\text { Unemployed }\end{array}$ & $\begin{array}{r}148(83.6) \\
27(15.3)\end{array}$ & $\begin{array}{r}124(63.3) \\
67(34.2)\end{array}$ & 0.007 \\
\hline $\begin{array}{l}\text { Alcohol drinking } \\
\text { No } \\
\text { Quit } \\
\text { Yes }\end{array}$ & $\begin{array}{r}28(15.8) \\
19(10.7) \\
130(73.4)\end{array}$ & $\begin{array}{l}90(45.2) \\
16(8.0) \\
93(46.7)\end{array}$ & $<0.001$ \\
\hline $\begin{array}{l}\text { Smoking } \\
\text { No } \\
\text { Quit } \\
\text { Yes }\end{array}$ & $\begin{array}{l}68(38.2) \\
41(23.0) \\
69(38.8)\end{array}$ & $\begin{aligned} 182 & (94.3) \\
5 & (2.6) \\
6 & (3.1)\end{aligned}$ & $<0.001$ \\
\hline $\begin{array}{l}\text { Vigorous exercise } \\
<20 \mathrm{~min} \times 3 \mathrm{~d} / \mathrm{wk} \\
\geq 20 \mathrm{~min} \times 3 \mathrm{~d} / \mathrm{wk}\end{array}$ & $\begin{array}{r}73(40.6) \\
107(59.4)\end{array}$ & $\begin{array}{r}178(86.4) \\
28(13.6)\end{array}$ & $<0.001$ \\
\hline $\begin{array}{l}\text { Center for Epidemiologic } \\
\text { Studies Depression Scale }\end{array}$ & $16.90 \pm 9.51$ & $18.51 \pm 11.01$ & 0.123 \\
\hline STAI_state & $44.47 \pm 11.02$ & $43.69 \pm 13.82$ & 0.538 \\
\hline STAI_trait & $45.20 \pm 9.11$ & $46.32 \pm 11.82$ & 0.294 \\
\hline EQ5D_index* & $0.947 \pm 0.082$ & $0.912 \pm 0.092$ & $<0.001$ \\
\hline EQ5D_visual analog scale & $73.42 \pm 14.61$ & $72.31 \pm 17.37$ & 0.505 \\
\hline
\end{tabular}

Values are presented as mean \pm standard deviation or number (\%).

STAI, State-Trait Anxiety Inventory; EQ5D, Euro quality of life.

*EQ5D_index is calculated based on result of 2007 KNHANES.

mean age was 43.10 years for men and 44.6 years for women. The proportion of college graduates was $68.2 \%$ of men and $42.9 \%$ of women; $74.2 \%$ of men and $67.7 \%$ of women were married. The health behaviors of our subjects, such as smoking and exercise, were similar to the results of the Korea National Health and Nutrition Examination Survey (Table 1). ${ }^{20)}$ The proportion of depressed persons (CES-D $\geq 21$ ) was $34.1 \%$ and $15 \%$ of all subjects had anxiety (STAI-S or STAI-T $\geq 57$ ).

\section{Factor Analysis of the Perceived Stress Inventory}

The PSI is a new 20-item instrument to measure perceived stress; it is comprised of 6 items from the SRI, 8 items from the PSQ, 2 items from the SCS, and 4 overlapping items from the SRI and SCS. Explorative factor analysis was again employed to determine the psychometric constructs of the new PSI. The 9-item short version was based on those psychometric constructs. The exploratory analyses with oblique rotation yielded three factors with an eigenvalue greater than 1: tension had an eigenvalue of 12.25 and explained $61.3 \%$ of the variance; depression had an eigenvalue of 1.17 and explained $5.8 \%$ of the variance; and anger had an eigenvalue of 1.00 and explained $4.9 \%$ of the variance. The explanatory powers of the second and third factors were similar. The factor loadings of each item were greater than 
Table 2. Factor analysis of Perceived Stress Inventory-long form

\begin{tabular}{|c|c|c|c|c|c|c|c|}
\hline Item no. & Items & Tension & Depression & Anger & $\begin{array}{c}\text { Items of } \\
\text { original } \\
\text { questionnaire }\end{array}$ & $\begin{array}{l}\text { Factors of original } \\
\text { questionnaire }\end{array}$ & Short version* \\
\hline 3 & My problems seem to be piling up. & 0.79 & 0.31 & 0.22 & PSQ 15 & Fatigue & 0 \\
\hline 2 & I fear I may not manage to attain my goals. & 0.78 & 0.19 & 0.13 & PSQ 9 & Worries & \\
\hline 1 & You don't feel rested. & 0.74 & 0.21 & 0.21 & PSQ 1 & Fatigue & \\
\hline 4 & I have many worries. & 0.74 & 0.34 & 0.34 & PSQ 18 & Fatigue & \\
\hline 7 & I feel mentally exhausted. & 0.70 & 0.45 & 0.28 & PSQ 26 & Tension & 0 \\
\hline 5 & I am afraid for the future. & 0.63 & 0.37 & 0.36 & PSQ 22 & Worries & \\
\hline 8 & I have trouble relaxing. & 0.61 & 0.39 & 0.35 & PSQ 27 & Tension & 0 \\
\hline 10 & I often sigh. & 0.61 & 0.42 & 0.46 & SRI 9 & Frustration & \\
\hline 12 & I have lost incentive to do anything. & 0.59 & 0.57 & 0.33 & SRI 19 & Depression & 0 \\
\hline 13 & I feel on edge. & 0.58 & 0.36 & 0.55 & SRI 21 & Anger & 0 \\
\hline 20 & I hate myself. & 0.26 & 0.78 & 0.23 & $\operatorname{SCS} 12$ & Extreme-negative & \\
\hline 17 & I am useless (or unworthy). & 0.14 & 0.77 & 0.37 & SRI 38 & Depression & \\
\hline 18 & I don't like moving any part of my body. & 0.43 & 0.69 & 0.18 & SRI 39 & Depression & \\
\hline 11 & I have lost my self-confidence. & 0.46 & 0.68 & 0.33 & SRI 15 & Depression & \\
\hline 19 & I don't like thinking anything. & 0.47 & 0.65 & 0.23 & $\operatorname{SCS} 10$ & Self-depreciative & 0 \\
\hline 6 & I feel criticized or judged. & 0.34 & 0.59 & 0.26 & PSQ 24 & Harassment & 0 \\
\hline 14 & I act violently (such as reckless driving, cursing, fighting). & 0.27 & 0.27 & 0.84 & SRI 28 & Aggression & \\
\hline 15 & I feel like breaking something. & 0.24 & 0.19 & 0.81 & SRI 29 & Aggression & 0 \\
\hline 16 & I have lost my patience. & 0.22 & 0.40 & 0.66 & SRI 36 & Anger & \\
\hline \multirow[t]{2}{*}{9} & I feel angry. & 0.56 & 0.36 & 0.59 & SRI 4 & Anger & 0 \\
\hline & Eigen value & 12.25 & 1.17 & 1.00 & & & \\
\hline
\end{tabular}

Bold figures indicate items greater than 0.5 of factor loading.

PSQ, Perceived Stress Questionnaire; SRI, Stress Response Inventory; SCS, Stress induced Cognition Scale.

${ }^{*} 0$ means items included in short version.

\subsection{The resulting three-factor model is shown in Table 2.}

Most items of the first factor, tension, were drawn from the PSQ factors of tension, fatigue, and worry. Items of the second factor, depression, were drawn from all three questionnaires' factors of depression or harassment. Items of the third factor, anger, were from the anger and aggression factors of the SRI (Table 2).

Confirmatory factor analysis was performed to determine the suitability of the PSI factor structure selected by the EFA. The standardized regression weights for each question were all greater than 0.5 ; average variance extracted values were all $\geq 0.5$ (tension, 0.591; depression, 0.600; anger, 0.625). Construct reliability was also greater than 0.7 (tension, 0.935 ; depression, 0.899 ; anger, 0.868 ). Therefore, the construct validity of the PSI is good.

\section{Reliability of the Perceived Stress Inventory}

All scores, including the total PSI and each of the three dimensions, were significantly correlated with each other. Each PSI item score was also highly correlated with the total score (range, 0.655 to 0.859 ) (Table 3 ). The short version also had significant correlations between the total and each item score (range, 0.625 to 0.846 ) (Table 4). The Cronbach's $\alpha$ value for the total score was 0.966 , and values for the three dimensions were greater than 0.8 . The test-retest reliability of the PSI scores was significant, ranging between 0.672 and 0.875 . The anger dimension showed the lowest correlation between the test and retest (Table 5). The Cronbach's $\alpha$ value of the short version was also rel- atively high (0.909, shown in Table 5). The correlation coefficient of the short version's test-retest scores was lower than that for the longer version.

\section{Validity of the Perceived Stress Inventory}

As expected, the total PSI score significantly correlated with those of the other stress measurements, SRI, PSQ, and PSS. We also found a small but significant correlation coefficient between the PSI and DSI scores. The tension dimension has many items from the PSQ and showed strong correlation with other stress measurements; for example, 0.851 between tension and the SRI. The PSI total score and three dimension scores showed large, significant correlations with anxiety and depression but a weak and negative correlation with both measures of QoL (Table 6). Unlike tension, anger had a weak correlation with anxiety and depression. We observed a similar correlation between the short version of the PSI and other stress measurements, but the associations were somewhat attenuated.

To measure the discriminant validity of the PSI, all subjects were divided into two groups: those with and without depressive mood according to CES-D scores. The anxious group was also separated from the healthy population using STAI scores. All scales differed between healthy adults and people with anxious or depressive mood. Both the depressive group and anxious group had consistently higher PSI scores than the healthy group (Table 6). 
Table 3. Item-total and item-subtotal correlation of Perceived Stress Inventory

\begin{tabular}{|c|c|c|c|c|c|}
\hline \multirow{2}{*}{ Item no. } & \multirow{2}{*}{ Items } & \multirow{2}{*}{$\begin{array}{l}\text { Item-total score } \\
\text { correlation* }\end{array}$} & \multicolumn{3}{|c|}{ Item-subtotal correlation } \\
\hline & & & Tension* & Depression* $^{*}$ & Anger* \\
\hline 1 & You don't feel rested. & 0.703 & 0.748 & & \\
\hline 2 & I fear I may not manage to attain my goals. & 0.691 & 0.756 & & \\
\hline 3 & My problems seem to be piling up. & 0.797 & 0.844 & & \\
\hline 4 & I have many worries. & 0.84 & 0.879 & & \\
\hline 5 & I am afraid for the future. & 0.796 & 0.816 & & \\
\hline 7 & I feel mentally exhausted. & 0.850 & 0.875 & & \\
\hline 8 & I have trouble relaxing. & 0.791 & 0.811 & & \\
\hline 10 & I often sigh. & 0.856 & 0.857 & & \\
\hline 12 & I have lost incentive to do anything. & 0.859 & 0.850 & & \\
\hline 13 & I feel on edge. & 0.859 & 0.858 & & \\
\hline 6 & I feel criticized or judged. & 0.682 & & 0.727 & \\
\hline 11 & I have lost my self-confidence. & 0.849 & & 0.871 & \\
\hline 17 & I am useless (or unworthy). & 0.686 & & 0.805 & \\
\hline 18 & I don't like moving any part of my body. & 0.764 & & 0.845 & \\
\hline 19 & I don't like thinking anything. & 0.800 & & 0.865 & \\
\hline 20 & I hate myself. & 0.723 & & 0.829 & \\
\hline 9 & I feel angry. & 0.855 & & & 0.863 \\
\hline 14 & I act violently (such as reckless driving, cursing, and fighting). & 0.742 & & & 0.899 \\
\hline 15 & I feel like breaking something. & 0.655 & & & 0.833 \\
\hline 16 & I have lost my patience. & 0.691 & & & 0.807 \\
\hline
\end{tabular}

*All $\mathrm{P}<0.01$.

Table 4. Item-total correlation of short version of PSI

\begin{tabular}{llll}
\hline $\begin{array}{l}\text { Items of original } \\
\text { questionnaire }\end{array}$ & \multicolumn{1}{c}{ Items } & Item-total correlation* & Factor of PSI \\
\hline PSQ15 & My problems seem to be piling up. & 0.728 & Tension \\
PSQ24 & I feel criticized or judged. & 0.625 & Depression \\
PSQ26 & I feel mentally exhausted. & 0.825 & Tension \\
PSQ27 & I have trouble relaxing. & 0.750 & Tension \\
SRI4 & I feel angry. & 0.823 & Anger \\
SRI19 & I have lost incentive to do anything. & 0.816 & Depression \\
SRI21 & I feel on edge. & 0.846 & Tensionsion \\
SRI29 & I feel like breaking something. & 0.719 & Anger \\
SCS 10 & I don't like thinking anything. & 0.700 & Depression
\end{tabular}

PSI, Perceived Stress Inventory; PSQ, Perceived Stress Questionnaire; SRI, Stress Response Inventory; SCS, Stress induced Cognition Scale.

${ }^{*}$ All $P<0.01$.

Table 5. Test-retest reliability and internal consistency of the long and short version of the Perceived Stress Inventory

\begin{tabular}{lcc}
\hline Variable & $\begin{array}{c}\text { Test-retest correlation }(\mathrm{N}=48) \\
\gamma^{*}\end{array}$ & $\begin{array}{c}\text { Internal consistency }(\mathrm{N}=387) \\
\text { Cronbach's } \alpha^{*}\end{array}$ \\
\hline Tension & $0.857^{*}$ & 0.95 \\
Depression & $0.847^{*}$ & 0.906 \\
Anger & $0.672^{*}$ & 0.873 \\
Total & $0.875^{*}$ & 0.966 \\
Short version & $0.726^{*}$ & 0.909 \\
\hline
\end{tabular}

$\gamma$ means Pearson's correlation coefficient.

${ }^{\star}$ All $P<0.01$.

\section{DISCUSSION}

The purpose of this study was to develop a new measure of perceived stress using items drawn from three other instruments for healthy Korean people. Exploratory factor analysis showed three scales in the new measure: tension, depression, and an- ger. This study also demonstrates the validity and reliability of both the long and short versions of the PSI.

The item pool for the new questionnaire came from three instruments suggested by previous research. We selected 20 items covering diverse facets of perceived stress reactions. The 8 items from the PSQ were originally included in the tension, fatigue, and worries dimensions of Levenstein et al. ${ }^{6}$ 's study, which used a population with gastroenterological problems. Those same items were categorized as worry and tension in the revised model of Fliege et al. ${ }^{7)}$ Tension can be regarded as an important concept in perceived stress and is a common dimension of stress measurements. As expected, the tension score in this study correlated highly with that in the PSS $(\gamma=0.723)$, which was higher than the dimensions of depression and anger. The PSI tension score also showed a strong association with tension and trait anxiety, similar to Levenstein et al. ${ }^{6)}$ 's study.

The dimensional structure of the PSI is meaningful for un- 
Table 6. Correlation of the score of PSI with other measurement and the difference according to anxiety or depressive mood ${ }^{\star}$

\begin{tabular}{|c|c|c|c|c|c|}
\hline \multirow{2}{*}{ Variable } & \multirow{2}{*}{ Short-version } & \multicolumn{4}{|c|}{ PSI } \\
\hline & & Total & Tension & Depression & Anger \\
\hline Daily Stress Inventory & 0.510 & 0.526 & 0.518 & 0.462 & 0.438 \\
\hline Stress Response Inventory & 0.762 & 0.878 & 0.851 & 0.798 & 0.780 \\
\hline Perceived Stress Questionnaire & 0.695 & 0.768 & 0.750 & 0.695 & 0.644 \\
\hline Perceived Stress Scale 10 & 0.584 & 0.716 & 0.723 & 0.601 & 0.548 \\
\hline CES-D & 0.661 & 0.817 & 0.778 & 0.783 & 0.670 \\
\hline STAI_S & 0.592 & 0.772 & 0.765 & 0.682 & 0.587 \\
\hline STAl_T & 0.638 & 0.799 & 0.791 & 0.720 & 0.628 \\
\hline EQ5D_index ${ }^{\dagger}$ & -0.269 & -0.341 & -0.366 & -0.328 & -0.227 \\
\hline EQ5d_visual analog scale & -0.424 & -0.502 & -0.493 & -0.470 & -0.392 \\
\hline \multicolumn{6}{|l|}{ CES-D } \\
\hline $\begin{array}{l}<21(\mathrm{~N}=255) \\
\geq 21(\mathrm{~N}=132)\end{array}$ & $\begin{array}{l}17.1 \pm 5.94 \\
26.0 \pm 7.44\end{array}$ & $\begin{array}{l}32.2 \pm 11.03 \\
56.3 \pm 16.31\end{array}$ & $\begin{array}{l}18.54 \pm 6.22 \\
31.34 \pm 8.97\end{array}$ & $\begin{array}{r}8.53 \pm 2.91 \\
15.24 \pm 5.14\end{array}$ & $\begin{array}{l}5.82 \pm 2.21 \\
9.72 \pm 4.01\end{array}$ \\
\hline \multicolumn{6}{|l|}{ STAI_S } \\
\hline $\begin{array}{l}<57(\mathrm{~N}=329) \\
\geq 57(\mathrm{~N}=58)\end{array}$ & $\begin{array}{l}18.5 \pm 6.75 \\
29.1 \pm 6.86\end{array}$ & $\begin{array}{l}35.7 \pm 13.14 \\
66.9 \pm 14.21\end{array}$ & $\begin{array}{l}20.41 \pm 7.32 \\
37.55 \pm 7.19\end{array}$ & $\begin{array}{r}9.57 \pm 3.67 \\
18.00 \pm 5.37\end{array}$ & $\begin{array}{r}6.33 \pm 2.61 \\
11.86 \pm 4.08\end{array}$ \\
\hline \multicolumn{6}{|l|}{ STAl_T } \\
\hline $\begin{array}{l}<57(\mathrm{~N}=329) \\
\geq 57(\mathrm{~N}=58)\end{array}$ & $\begin{array}{l}18.5 \pm 6.63 \\
29.1 \pm 7.14\end{array}$ & $\begin{array}{l}35.7 \pm 13.15 \\
66.1 \pm 14.74\end{array}$ & $\begin{array}{l}20.39 \pm 7.29 \\
37.09 \pm 7.68\end{array}$ & $\begin{array}{r}9.57 \pm 3.71 \\
17.73 \pm 5.37\end{array}$ & $\begin{array}{r}6.33 \pm 2.71 \\
11.58 \pm 3.85\end{array}$ \\
\hline
\end{tabular}

PSI, Perceived Stress Inventory; CES-D, Center for Epidemiologic Studies Depression Scale; STAl_S, State-Trait Anxiety Inventory_state; STAl_T, State-Trait Anxiety Inventory_ trait; EQ5D, Euro QoL index.

${ }^{*}$ All $\mathrm{P}<0.01$. ${ }^{\mathrm{E} Q 5 \mathrm{D}}$ index is calculated based on result of 2007 Korea National Health and Nutrition Examination Survey. EQ-5D $=1-(0.05+0.096 \times \mathrm{M} 2+0.418 \times \mathrm{M} 3+0.046$ $\times \mathrm{SC} 2+0.136 \times \mathrm{SC} 3+0.051 \times \mathrm{UA} 2+0.208 \times \mathrm{UA} 3+0.037 \times \mathrm{PD} 2+0.151 \times \mathrm{PD} 3+0.043 \times \mathrm{AD} 2+0.158 \times \mathrm{AD} 3+0.05 \times \mathrm{N} 3)$

derstanding perceived stress in a Korean population. We propose an anger dimension in the new questionnaire based on many items from the SRI or SCS, which were developed in Korea. Anger is frequently reported as a unique aspect of the Korean stress response, unlike in Western society. For example, the Korean culture-related anger syndrome Hwa-byung has been reported and included in the appendix of the DSM (diagnostic and statistical manual of mental disorders)-IV. ${ }^{21)}$ This disease is believed to be related to the special culture of Korea, including familial collectivism and social suppression by the ruling class. ${ }^{22,23)}$ Thus, anger, one dimension of the PSI, is a stress response influenced by culture. The scale for anger showed good validity with depression and anxiety but relatively lesser reliability because it is temporary in nature.

Some SRI items were initially excluded from the item pool. The SRI has 39 items and a seven-factor model (tension, aggression, somatization, anger, depression, fatigue, and frustration) according to the original study. Unlike the dimensions of the original SRI, Choi et al. ${ }^{10)}$ identified the somatization dimension using items such as "I suffer from indigestion," or "I feel dizzy." Those items reflect a somatic response rather than perceived stress, so we excluded them as inappropriate to the purpose of the new measurement. The PSS was not included in the item pool, even though it is widely used, because its content is nonspecific and without subscales. However, the PSS is based on the idea that stress results from experience overload, with further emphasis on the unpredictability and uncontrollability of events. ${ }^{24,25)}$ The PSS score showed significant correlation with the new measure.
The recently published Brief Inventory of Perceived Stress $(B I P S)^{26)}$ consists of 9 items drawn from the PSQ and PSS in order to compensate for the poor model fit of the PSS. ${ }^{13,26)}$ Lahman et al. proposed a three-factor model with 8 PSQ items and 1 PSS item, two of which are included in the tension and depression scales of the PSI. The most important advantage of the BIPS is its short questionnaire, possible for quick administration, which is similar to the short version of the PSI. Both questionnaires are useful instruments for measuring perceived stress in a population survey. However, the BIPS has a threefactor model with a different psychometric structure (lack of control, pushed, and conflict and imposition) to that of the PSI. This means each instrument reflects a different way of understanding perceived stress. The different content structure of both instruments comes from cultural influences on the stress concept. The strong correlation between the PSI short version and the PSS, CES-D, and STAI-T confirmed the good criterion validity of the short version, even though it has unique dimensions.

The purpose of the Perceived Stress Inventory (PSI) development is use for population surveys. The strength of this study is that the age and sex composition of the subjects was similar to that of the 2009 census data. ${ }^{12)}$ In addition, we tried to minimize the influence of personal health status on the stress reactions being measured. The content and criterion validity of the PSI were confirmed using factor analysis and correlation analysis in a healthy population. Though this study design is good for generalizing our findings, further study using a national survey is necessary to generalize it even more broadly. Another 
strength of our work is the unique psychometric structure of the PSI that includes anger, which is an important factor in Korean culture. Anger is commonly associated with depression or anxiety in Korea. ${ }^{27)}$ However, it is not found in instruments developed in Western cultures. Further study would thus be necessary to generalize this instrument to Western society.

The PSI, a new instrument for measuring perceived stress, has a three-factor construct and excellent reliability and validity in healthy Korean adults. It measures three dimensions with acceptable psychometric properties and can be useful for population surveys. The short version of the PSI, with similar reliability and validity, could be even more feasible for surveys or clinical practice because of its brevity.

\section{CONFLICT OF INTEREST}

No potential conflict of interest relevant to this article was reported.

\section{ACKNOWLEDGMENTS}

Financial Support: This study was supported by a grant (2010E00690-00) from the Research of Korea Centers for Disease Control \& Prevention.

\section{REFERENCES}

1. Richardson S, Shaffer JA, Falzon L, Krupka D, Davidson KW, Edmondson D. Meta-analysis of perceived stress and its association with incident coronary heart disease. Am J Cardiol 2012;110:1711-6.

2. Vinkers CH, Joels M, Milaneschi Y, Kahn RS, Penninx BW, Boks MP. Stress exposure across the life span cumulatively increases depression risk and is moderated by neuroticism. Depress Anxiety 2014;31:737-45.

3. Huang J, Valdimarsdottir U, Fall K, Ye W, Fang F. Pancreatic cancer risk after loss of a child: a register-based study in Sweden during 1991-2009. Am J Epidemiol 2013;178:582-9.

4. Chen YH, Lin HC. Increased risk of cancer subsequent to severe depression: a nationwide population-based study. J Affect Disord 2011; 131:200-6.

5. DeLongis A, Folkman S, Lazarus RS. The impact of daily stress on health and mood: psychological and social resources as mediators. J Pers Soc Psychol 1988;54:486-95.

6. Levenstein S, Prantera C, Varvo V, Scribano ML, Berto E, Luzi C, et al. Development of the Perceived Stress Questionnaire: a new tool for psychosomatic research. J Psychosom Res 1993;37:19-32.

7. Fliege H, Rose M, Arck P, Walter OB, Kocalevent RD, Weber C, et al. The Perceived Stress Questionnaire (PSQ) reconsidered: validation and reference values from different clinical and healthy adult samples. Psychosom Med 2005;67:78-88.
8. Koh KB, Park JK, Kim CH, Cho S. Development of the stress response inventory and its application in clinical practice. Psychosom Med 2001; 63:668-78.

9. Koh KB, Park JK, Cho S. Development of the stress-induced cognition scale. Yonsei Med J 2006;47:384-92.

10. Choi SM, Kang TY, Woo JM. Development and validation of a modified form of the stress response inventory for workers. J Korean Neuropsychiatr Assoc 2006;45:541-53.

11. Lee EH, Chung BY, Suh CH, Jung JY. Korean versions of the Perceived Stress Scale (PSS-14, 10 and 4): psychometric evaluation in patients with chronic disease. Scand J Caring Sci 2015;29:183-92.

12. Korean Statistical Information Service. Projected population by age and sex [Internet]. Daejeon: Statistics Korea [cited 2010 Jan 30]. Available from: http://kosis.kr/.

13. Lee J, Shin C, Ko YH, Lim J, Joe SH, Kim S, et al. The reliability and validity studies of the Korean version of the Perceived Stress Scale. Korean J Psychosom Med 2012;20:127-34.

14. Kim JJ, Shin CJ, Chung IW. A reliability and validity of Korean version of Daily Stress Inventory. J Korean Neuropsychiatr Assoc 1998;37:295305.

15. Brantley PJ, Waggoner CD, Jones GN, Rappaport NB. A Daily Stress Inventory: development, reliability, and validity. J Behav Med 1987;10:6174.

16. Han KS, Lee PS, Lee YM. Influencing factors on symptoms of stress of middle aged women. J Korean Acad Nurs 2000;30:1427-36.

17. Cho MJ, Kim KH. Diagnostic validity of the CES-D (Korean version) in the assessment of DSM-III-R major depression. J Korean Neuropsychiatr Assoc 1993;32:381-99.

18. Hahn DW, Lee CH, Chon KK. Korean adaptation of Spielberger's STAI (K-STAI). Korean J Health Psychol 1996;1:1-14.

19. Kim MH, Cho YS, Uhm WS, Kim S, Bae SC. Cross-cultural adaptation and validation of the Korean version of the EQ-5D in patients with rheumatic diseases. Qual Life Res 2005;14:1401-6.

20. Lee HO, Bak HJ, Shin JY, Song YM. Association between metabolic syndrome and microalbuminuria in Korean adults. Korean J Fam Med 2015;36:60-71.

21. American Psychiatric Association. Diagnostic and statistical manual of mental disorders, text revision. 4th ed. Washington (DC): American Psychiatric Association; 2000.

22. Min SK. A study on the concept of hwa-byung. J Korean Neuropsychiatr Assoc 1989;28:604-61.

23. Min SK. Hwa-byung and the psychology of haan. J Korean Med Assoc 1991;34:1189-98.

24. Cohen S, Kamarck T, Mermelstein R. A global measure of perceived stress. J Health Soc Behav 1983;24:385-96.

25. Golden-Kreutz DM, Browne MW, Frierson GM, Andersen BL. Assessing stress in cancer patients: a second-order factor analysis model for the Perceived Stress Scale. Assessment 2004;11:216-23.

26. Lehman KA, Burns MN, Gagen EC, Mohr DC. Development of the brief inventory of perceived stress. J Clin Psychol 2012;68:631-44.

27. Min SK, Suh SY. The anger syndrome hwa-byung and its comorbidity. J Affect Disord 2010;124:211-4. 
Appendix 1. Perceived Stress Inventory

\section{1) Long version of Perceived Stress Inventory}

다음 문항들은 여러분이 경험했던 사건들을 생각하면서 각 항목의 느낌이 지난 한 달간 어느 정도로 경험했는지를 해당되는 빈칸에 $\bigcirc$ 표를 하십시오. 오래 생 각하시지 말고 최대한 빨리 응답해 주세요. 그리고 문항을 하나도 빠뜨리지 말고 반드시 한 곳에만 표시하십시오.

\begin{tabular}{|c|c|c|c|c|c|c|}
\hline & 문항 & $\begin{array}{c}\text { 전혀 } \\
\text { 그렇지 않다 }\end{array}$ & $\begin{array}{c}\text { 약간 } \\
\text { 그렇다 }\end{array}$ & $\begin{array}{l}\text { 웬만큼 } \\
\text { 그렇다 }\end{array}$ & $\begin{array}{l}\text { 상당히 } \\
\text { 그렇다 }\end{array}$ & $\begin{array}{c}\text { 아주 } \\
\text { 그렇다 }\end{array}$ \\
\hline 1 & 마음이 편안하지 않다. & 1 & 2 & 3 & 4 & 5 \\
\hline 2 & 나의 목표를 달성하지 못할까 두렵다. & 1 & 2 & 3 & 4 & 5 \\
\hline 3 & 문제들이 풀리지 않고 계속 쌓이는 느낌이다. & 1 & 2 & 3 & 4 & 5 \\
\hline 4 & 걱정이 많다. & 1 & 2 & 3 & 4 & 5 \\
\hline 5 & 내게 닥쳐 올 미래가 두렵다. & 1 & 2 & 3 & 4 & 5 \\
\hline 6 & 다른 사람으로부터 비난 받거나 심판 받는다고 느껴진다. & 1 & 2 & 3 & 4 & 5 \\
\hline 7 & 정신적으로 지친다. & 1 & 2 & 3 & 4 & 5 \\
\hline 8 & 긴장을 풀기 어렵다. & 1 & 2 & 3 & 4 & 5 \\
\hline 9 & 화가 난다. & 1 & 2 & 3 & 4 & 5 \\
\hline 10 & 한숨이 나온다. & 1 & 2 & 3 & 4 & 5 \\
\hline 11 & 자신감을 잃었다. & 1 & 2 & 3 & 4 & 5 \\
\hline 12 & 의욕이 떨어진다. & 1 & 2 & 3 & 4 & 5 \\
\hline 13 & 신경이 날카로워졌다 & 1 & 2 & 3 & 4 & 5 \\
\hline 14 & 행동이 거칠어졌다(난폭운전, 욕설, 몸싸움 등). & 1 & 2 & 3 & 4 & 5 \\
\hline 15 & 무언가를 부수고 싶다. & 1 & 2 & 3 & 4 & 5 \\
\hline 16 & 참을성이 없다. & 1 & 2 & 3 & 4 & 5 \\
\hline 17 & 나는 아무 쓸모 없는 사람이다. & 1 & 2 & 3 & 4 & 5 \\
\hline 18 & 움직이기 싫다. & 1 & 2 & 3 & 4 & 5 \\
\hline 19 & 아무런 생각을 하고 싶지 않다. & 1 & 2 & 3 & 4 & 5 \\
\hline 20 & 내 자신이 싫다. & 1 & 2 & 3 & 4 & 5 \\
\hline
\end{tabular}

\section{2) Short version of Perceived Stress Inventory}

다음 문항들은 여러분이 경험했던 사건들을 생각하면서 지난 한 달간 각 항목의 느낌을 어느 정도로 경험했는지를 해당되는 빈칸에 $\bigcirc$ 표를 하십시오. 오래 생 각하시지 말고 최대한 빨리 응답해 주세요. 문항을 하나도 빠뜨리지 말고 반드시 한 곳에만 표시해 주십시오.

\begin{tabular}{|c|c|c|c|c|c|c|}
\hline & 문항 & $\begin{array}{c}\text { 전혀 } \\
\text { 그렇지 않다 }\end{array}$ & $\begin{array}{l}\text { 약간 } \\
\text { 그렇다 }\end{array}$ & $\begin{array}{l}\text { 웬만큼 } \\
\text { 그렇다 }\end{array}$ & $\begin{array}{l}\text { 상당히 } \\
\text { 그렇다 }\end{array}$ & $\begin{array}{l}\text { 아주 } \\
\text { 그렇다 }\end{array}$ \\
\hline 1 & 문제들이 풀리지 않고 계속 쌓이는 느낌이다. & 1 & 2 & 3 & 4 & 5 \\
\hline 2 & 다른 사람으로부터 비난받거나 심판받는다고 느껴진다. & 1 & 2 & 3 & 4 & 5 \\
\hline 3 & 정신적으로 지친다. & 1 & 2 & 3 & 4 & 5 \\
\hline 4 & 긴장을 풀기 어렵다. & 1 & 2 & 3 & 4 & 5 \\
\hline 5 & 화가 난다. & 1 & 2 & 3 & 4 & 5 \\
\hline 6 & 의욕이 떨어진다. & 1 & 2 & 3 & 4 & 5 \\
\hline 7 & 신경이 날카로워졌다. & 1 & 2 & 3 & 4 & 5 \\
\hline 8 & 무언가를 부수고 싶다. & 1 & 2 & 3 & 4 & 5 \\
\hline 9 & 아무런 생각을 하고 싶지 않다. & 1 & 2 & 3 & 4 & 5 \\
\hline
\end{tabular}

